\title{
An investigation of the beneficial effects of adding carbon nanotubes to standard injection grout
}

\author{
L. Restuccia ${ }^{1}$ (I) । A. Lopez ${ }^{1}$ | G.A. Ferro ${ }^{1}$ (D) । D. Liberatore ${ }^{2}$ (D) । J.M. Tulliani ${ }^{3}$ (C)
}

\author{
${ }^{1}$ Department of Structural, Geotechnical and \\ Building Engineering, Politecnico di Torino, \\ 10129 Turin, Italy \\ ${ }^{2}$ Department of Structural and Geotechnical \\ Engineering, "Sapienza" University of \\ Rome, 00197 Rome, Italy \\ ${ }^{3}$ Department of Applied Science and \\ Technology, Politecnico di Torino, 10129 \\ Turin, Italy

\section{Correspondence} \\ G A Ferro, Department of Structural, \\ Geotechnical and Building Engineering, \\ Politecnico di Torino, 10129 Turin, Italy. \\ Email: ferro@polito.it
}

\begin{abstract}
Mortar grouting is often used in masonry constructions to mitigate structural decay and repair damage by filling cracks and voids, resulting in an improvement in mechanical properties. This paper presents an original experimental investigation on grout with added carbon nanotubes (CNTs). The samples were prepared with different percentages of CNTs, up to $1.2 \mathrm{wt} \%$ with respect to the binder, and underwent three-point bending tests in crack mouth opening displacement mode and compressive tests. The results showed that very small additions (up to $0.12 \mathrm{wt} \%$ of CNTs) increased not only flexural and compressive strengths ( $+73 \%$ and $35 \%$, respectively, in comparison with plain mortar) but also fracture energy $(+80 \%)$. These results can be explained on the basis of a reduction in porosity, as evidenced by mercury intrusion porosimetry, as well as by a crack bridging mechanism and by the probable formation of nucleation sites for hydration products, as observed through scanning electron microscopy.
\end{abstract}

\section{KEYWORDS}

carbon nanotubes, fracture energy, grouting, innovative mix design, mechanical properties

\section{1 | INTRODUCTION}

Masonry is a classically built structure consisting of units, either stones or bricks, and a suitable mortar binder. The mechanical characteristics of the units and the quality of the mortar and fabric play an important role in its structural performance and durability, especially under seismic actions. ${ }^{1,2}$

\footnotetext{
Nomenclature: CNTs, carbon nanotubes; C-S-H, calcium silicate hydrate; MWCNTs, multiwalled carbon nanotubes; ASTM, American Society for Testing and Materials; TPB, three-point bending test; CMOD, crack mouth opening displacement; $G_{F}$, fracture energy; $W_{0}$, area referred to load; $m_{1}$, weight of the beam between the supports; $m_{2}$, weight of the part of the loading system that is not attached to the machine but follows the beam until failure; $g$, acceleration due to gravity; $\delta_{0}$, deformation at final failure of the beam; $A_{\text {lig }}$, area of the ligament; $\sigma_{\text {fmax }}$, modulus of rupture; L, span; $\mathrm{b}$, specimen depth; $\mathrm{h}$, net ligament height; $\lambda$, anticathode wavelength; XRD, X-ray diffraction; FE-SEM, Field emission-scanning electron microscopy; MIP, Mercury intrusion porosimetry; TG-DTA, Thermogravimetric-differential thermal analysis; EDX, Energy dispersive $\mathrm{X}$-ray analysis
}

Typically, the collapse of existing masonry structures is triggered by crumbling, out-of-plane (overturning or bending), or in-plane (shear or bending) mechanisms of the load-bearing structures. Crumbling is usually the most dangerous and can lead to the separation of masonry leaves and to the collapse of large portions or all of the masonry construction. Therefore, the highest priority is to prevent the onset of the conditions that trigger the crumbling mechanism. Good quality mortar is essential to retard/avoid these conditions and prevent the separation of leaves.

Deterioration phenomena appear in mortars as well as in units. The quality of both and the quality of the bond between the mortar and the units decrease with time. The gravitational loads on the walls normally induce vertical compressive stresses in the masonry. It must be highlighted that compressive stresses are usually not harmful to masonry. However, close to structural discontinuities such as cracks, voids, holes, and pores, tensile stresses are present at the contact surfaces between stones and mortar. ${ }^{1}$ Their magnitude is of the same 
order as the compressive stresses. Thus, tensile stresses can cause cracking or microcracking in stones, mortar, or in the bond between them. Furthermore, dynamic loadings like vibrations, earthquakes, shocks, and wind loads can increase this cracking phenomenon. Bearing in mind that tensile stresses might cause masonry failure, it is evident that an increase in the tensile strength of masonry results in an improvement in structural performance. ${ }^{1}$

Grout injection is one of the most widely used techniques in the structural rehabilitation of ancient/old masonry to restore an acceptable performance of the binder when decayed or damaged. ${ }^{3}$ The injection of grout should mainly fill cracks and voids present in the masonry, replacing most of the old mortar, thus assuring a homogeneous bond between the mortar and the units, the aim being to restore the original structural characteristics.

Besides helping to restore bonding strength, grouts adopted for injection should also feature other important qualities, like fluidity, ductility, and bond durability. Improvement in the mechanical behavior of an ancient/old structure requires the development of a mortar with optimum properties in injectability and adhesion, so that small cracks and voids may be filled and structural continuity inside the masonry assured. ${ }^{1}$

Should a grout composition not comply with the abovementioned quality and performance requirements, its use may not reach the required level of structural strength, or worse, jeopardize the structural characteristics of old masonries. ${ }^{4}$ In Table 1, a brief summary is given of the design requirements, adapted from ${ }^{5}$ for grout that can improve/ restore the mechanical behavior of the injected structure.

TABLE 1 Grout requirements in the mechanical behavior of the injected structure ${ }^{5}$

\begin{tabular}{|c|c|}
\hline Requirements & Description \\
\hline Injectability & $\begin{array}{l}{ }^{\circ} \text { Low yield value and viscosity } \\
{ }^{\circ} \text { Penetrability: in voids with } \\
\text { diameter smaller than } 0.3 \mathrm{~mm} \\
{ }^{\circ} \text { Stability: no substantial density } \\
\text { gradients along the height of } \\
\text { the stored grout } \\
{ }^{\circ} \text { Low bleeding: lower than } 5 \% \\
\text { after } 120 \text { minute rest }\end{array}$ \\
\hline $\begin{array}{l}\text { Bonding with existing } \\
\text { materials }\end{array}$ & $\begin{array}{l}{ }^{\circ} \text { Relatively low shrinkage (although } \\
\text { autogenous shrinkage is unavoidable) } \\
{ }^{\circ} \text { Minimal heat of hydration } \\
{ }^{\circ} \text { Setting and hardening in dry as } \\
\text { well as in wet environment }\end{array}$ \\
\hline $\begin{array}{l}\text { Sufficient mechanical } \\
\text { properties within a } \\
\text { defined time span }\end{array}$ & $\begin{array}{l}{ }^{\circ} \text { Development of the required } \\
\text { mechanical properties in } 90 \text { days } \\
{ }^{\circ} \text { Compressive and flexural strengths } \\
\text { dictated by structural analysis }\end{array}$ \\
\hline
\end{tabular}

Owing to the design requirements identified above and taking into account the peculiar chemical and physical characteristics of carbon nanotubes (CNTs), it was considered useful to devise a compatible mixture between a standard commercial grout powder and CNTs, one that could create synergy in the resulting matrix of the grouting mortar.

Carbon nanotubes are considered to be, by their nature, inert materials, while their specific characteristics point to an extended binding effect within the resulting matrix, as indicated in available literature.

Due to their exceptional mechanical properties, CNTs have been extensively used in research and test activity as reinforcing fibres in cement and concrete. Four main reinforcing mechanisms have been identified in cementitious matrices with added CNTs. ${ }^{6}$ The primary one is the crack bridging mechanism, as CNTs can bridge gaps in the range of 10 to $10^{3} \mathrm{~nm}$ within hydration products. ${ }^{7,8}$ Moreover, the bridging effect of CNTs provides efficient load transfer from the matrix to the CNTs within the composites and delays crack growth. ${ }^{9}$ Thus, the mechanical properties are strongly influenced by the amount of load transfer from the matrix to the CNTs within the composites. From an energy point of view, the cement matrix crack growth process is one of energy consumption. Therefore, a stronger force, and hence a higher amount of energy, is required to break the crack bridging of CNTs. Furthermore, CNTs reduce the nanoporosity of cement paste by filling pores between hydrated products. ${ }^{10-12}$ Carbon nanotubes are also able to modify the microstructure of hydration products. New compounds were observed due to the chemical bonds between CNTs and hydrated phases. ${ }^{13-15}$ For example, composites seem to contain a higher amount of high stiffness C-S-H (calcium silicate hydrate) gel. ${ }^{10}$ Finally, CNTs can play a role as nucleating agents for C-S-H gel. ${ }^{8,16,17}$ This may lead to a reduction in specific reinforcements and an increase in durability. On the other hand, the dispersion difficulties of CNTs and their relative high price would seem to limit, for the time being, the practical application of this type of "microfibre" in cement-based composite materials. ${ }^{18}$

When the microstructure of the material is changed by adding nanoparticles or CNTs, some additional considerations have to be fronted, ${ }^{19}$ as well as when nonstandard specimen dimensions are used for evaluating mechanical properties, in particular for fracture energy. ${ }^{20,21}$

While a suitable dispersion and an acceptable interface bonding between CNTs and the mortar matrix are fundamental to increase the mechanical characteristics of resulting mortar nanocomposites, ${ }^{22}$ the nature of CNTs means that they are neither soluble in the aqueous liquid in which they are dispersed to form a suspension nor do they chemically interact with the hydrated mortar phases. Therefore, the research community still considers it an essential target to achieve a practically acceptable dispersion of CNTs in the cement/mortar resulting matrix through surface modification/functionalization 
chemical processes. However, acid functionalization of CNTs can lead to an increase in CNT toxicity. ${ }^{23}$

The addition of CNTs in grout is to be considered a novelty. In fact, although literature on cement-CNT composites is extremely detailed and prolific, no specific research on CNTgrout injection composite is yet available.

This first research on grout-CNTs focuses primarily on the beneficial effect that grout paste with added carbon nanoparticles, ie, CNTs in this case, may have on the mechanical and durability properties of the resulting injection grout composite. To the best of our knowledge, this has never been done before.

To have a realistic binary mortar mix, the choice was made to use mortar powder and CNTs already available commercially. This approach allows for the development of a reproducible CNT-grout nanocomposite for future research minimizing the number of factors that might influence preparation and testing of the resulting composite.

On these bases, both multiwalled CNTs (MWCNTs) and the injection mortar powder utilized in the research were purchased: MWCNT Nanocyl 7000 series are produced by the Belgian Company Nanocyl SA, while the injection mortar Mape Antique I is produced by the Italian Company Mapei.

Test samples were prepared by adding a CNT weight percentage in the range of 0.025 to $0.8 \%$ of the grout weight. Flexural and compressive strengths, as well as fracture energy, were then studied.

\section{2 | MATERIALS AND METHODS}

\section{1 | Materials}

The materials used for the preparation of the test articles of the present investigation were as follows:

- Mapei Mape Antique I: ready to use and cement-free filled hydraulic binder based on lime, pozzolan, and sand, formulated in a fine powder $(<100 \mu \mathrm{m})$. It is salt-resistant and is used to grout cracks in masonry. When mixed with approximately $35 \%$ water, it produces a stable fluid slurry that can fill cavities in structures in need of consolidation. ${ }^{24}$ The constituents of "Mapei Mape Antique I" cannot be reported because this product is a commercially available injection grout covered by Mapei Copyrights, so that the complete mix specification of this grout product is not made available by the company except for the data given in Table 2 below.

- Water: Deionized water was used for mixing procedure and tap water for curing procedures.

- Multiwalled CNTs: industrial MWCNTs from Nanocyl (7000 series), produced via the catalytic chemical vapor deposition process. They were chosen for good workability and cost in use ratio (Table 3 ).
TABLE 2 Features of Mapei Mape Antique I according to the producer

\begin{tabular}{ll}
\hline Features of MWCNTs & \\
\hline Grain Size $[\mu \mathrm{m}]$ & 100 \\
\hline Volumetric mass $\left[\mathrm{kg} / \mathrm{m}^{3}\right]$ & 1100 \\
\hline Water/binder mix ratio [\%] & $7 \mathrm{~L}$ for $20 \mathrm{~kg} 35$ \\
\hline Bleeding & Nil \\
\hline $\begin{array}{l}\text { Volumetric mass of freshly } \\
\text { made grout }\left[\mathrm{kg} / \mathrm{m}^{3}\right]\end{array}$ & 1900 \\
$\begin{array}{l}\text { Fluidity } \\
\begin{array}{l}\text { Compression strength after } \\
28 \text { days }[\mathrm{MPa}]\end{array}\end{array}$ & $<30$ (initial), $<30$ (final) \\
\hline $\begin{array}{l}\text { Flexural strength after } 28 \text { days }[\mathrm{MPa}] \\
\text { Young modulus after } 28 \text { days }[\mathrm{MPa}]\end{array}$ & Not available \\
\hline
\end{tabular}

TABLE 3 Features of the multiwalled carbon nanotubes (MWCNTs) used according to the producer

\begin{tabular}{lc} 
Features of MWCNTs & \\
\hline Average diameter [nm] & $40-80$ \\
\hline Length (average) $[\mu \mathrm{m}]$ & $400-1000$ \\
Carbon purity [wt $\%$ ] & $>92$ \\
Metal oxide (impurity) [wt $\%$ ] & $<6$ \\
\hline
\end{tabular}

\section{2 | Methods}

Mape Antique I contains about $50 \%$ filler, ${ }^{24}$ so addition of CNTs was based on the weight percentage of the binder. Table 5 below gives the weight and percentage of CNTs and Mape Antique powder to produce a CNT mortar mixture required for a set of 3 standard prismatic moulds $(40 \times 40 \times 160 \mathrm{~mm})$.

Sample notations A and B identify 2 different batches of the CNT-mortar specimen preparation in the research, produced in 2 different days due to formwork availability.

To fill the standard metal formwork of 3 specimens, a quantity of $1.2 \mathrm{~kg}$ of dry mortar was used. Carbon nanotubes are available as dry material, and a simple, reliable, and scalable process for deagglomeration is required to use them to their maximum potential.

For the research-type specimens, in accordance with American Society for Testing and Materials (ASTM) C-348 standard, the same procedure was always followed. First, the amount of Mapei Dynamon SP 2 super plasticizer was mixed with water, as detailed in Table 4. At this point, the MWCNTs were dispersed into the solution based on water + super plasticizer by means of a standard stirrer, and then by sonication for 3 hours before CNT-mortar addition. Due to 30\% sonication power limitation (with cycles of 30 seconds on-off; Sonics 
Vibra Cell VC750, $750 \mathrm{~W}$ power) and the water weight required for injection grout mixing, sonication was carried out in 3 steps with increasing water weight (Table 4).

Then, CNT-mortar composite specimens were prepared by slowly adding Mape Antique I powder to the mixture of water-dispersed MWCNTs by means of a mixer (Hobart Model N-50) at low speed. Once a homogeneous paste had been obtained, the last step of mixing was carried out for 5 minutes at medium speed. After the mixing and dispersing procedure, each grout was cast into the mould and kept in a humid atmosphere at room temperature for 5 days. Then, they were removed from the moulds and cured for 21 days in the same conditions. Every specimen was notched, by using a Remet Type TR100S saw, with a $2 \mathrm{~mm}$ thickness diamond cut-off wheel. The notch depth for the specimens was $12 \mathrm{~mm}$.

The process proved acceptable and easy to handle, as shown by the overall results.

\section{3 | MECHANICAL TESTS AND PHYSICOCHEMICAL CHARACTERIZATION}

The specimens underwent a three-point bending test (TPB) and a compressive test. After the completion of the mechanical tests, physicochemical characterization was also carried out.

\section{1 | Mechanical tests}

For each notched sample, TPBs were carried out after 28 curing days.

The experimental tests were performed by using a $100 \mathrm{kN}$ MTS servo-controlled machine and by imposing a constant increment of crack mouth opening displacement (CMOD; Figure 1). To this end, a clip-on gauge was used to control displacement during the test. The data were recorded at $10 \mathrm{~Hz}$ by using a specific data acquisition system. Complementary to the MTS machine data, a back-up database was recorded at $1 \mathrm{~Hz}$ by a CatMan system, providing a real-time graphical interface for the test operator.

The load was applied by imposing a testing crossbar speed of $5 \cdot 10^{-4} \mathrm{~mm} / \mathrm{s}$ and adopting a span of $150 \mathrm{~mm}$.

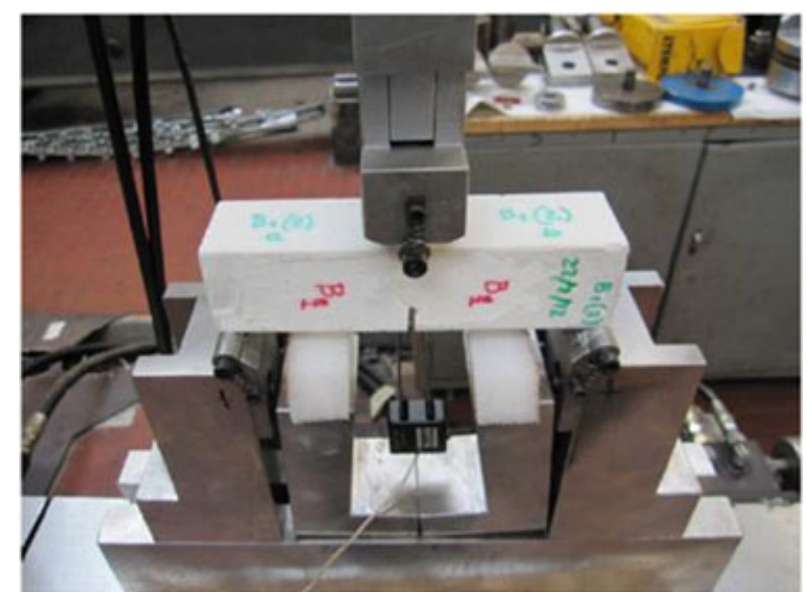

FIGURE 1 Three-point bending (TPB) test configuration [Colour figure can be viewed at wileyonlinelibrary.com]

Fracture energy $G_{F}$ is represented by the area under the curve load/CMOD [N/mm]. It is measured, as also deformation $\delta_{0}$ at final failure. ${ }^{25}$

Following RILEM recommendation $50-\mathrm{FMC},{ }^{25}$ fracture energy is calculated according to Equation 1:

$$
G_{F}=W_{0}+m g \delta_{0} / A_{\text {lig }}[\mathrm{N} / \mathrm{m}]
$$

where

$W_{0} \quad=$ area referred to load/CMOD $[\mathrm{N} / \mathrm{m}] ;$

$m=m_{1}+m_{2}$, where $m_{1}$ is the weight of the beam between the supports and $m_{2}$ is the weight of the part of the loading system that is not attached to the machine but follows the beam until failure $[\mathrm{kg}]$;

$g \quad=$ acceleration due to gravity $\left[\mathrm{m} / \mathrm{s}^{2}\right]$;

$\delta_{0} \quad=$ deformation at final failure of the beam [m]; and

$A_{\text {lig }} \quad=$ area of the ligament $\left[\mathrm{m}^{2}\right]$.

However, it was not possible to use this equation for the reduction of the test data because the three-point flexural test setup configuration used for tests did not include a transducer that could measure $\delta_{0}$, as seen in Figure 1 . Therefore, only load and CMOD test data were used to calculate fracture energy, $G_{F}$, by means of OriginLab software (OriginPro 8.5, OriginLab Corporation, USA).

For the purposes of the research, this was considered acceptable because it was only a preliminary investigation to assess how the addition of CNTs to mortar could improve

TABLE 4 Multiwalled carbon nanotube (MWCNT)-water sonication

\begin{tabular}{|c|c|c|c|c|c|c|c|}
\hline Parameter & $\begin{array}{c}\text { Specimen } \\
\text { Dimensions }\end{array}$ & $\begin{array}{l}\text { W/C } \\
\text { Ratio }\end{array}$ & $\begin{array}{c}\text { Super Plasticizer } \\
\text { (SP)/C }\end{array}$ & 1st Step & 2nd Step & 3rd Step & Total \\
\hline $\begin{array}{r}\text { Sonication time } \\
\text { [30\% power] }\end{array}$ & $40 \times 40 \times 160 \mathrm{~mm}$ & 0.35 & $1 \mathrm{~g}$ & 1 hour & 1 hour & 1 hour & 3 hours \\
\hline Mixing water & & & & $33.33 \%$ & $66.66 \%$ & $100 \%$ & \\
\hline Super plasticizer weight & & & & $140 \mathrm{~g}$ & $280 \mathrm{~g}$ & $420 \mathrm{~g}$ & $420 \mathrm{~g}$ \\
\hline
\end{tabular}


the mechanical properties of the resulting composite. Even though the $G_{F}$ values obtained may be considered "raw," the relative difference between the mechanical properties of the basic mortar and the ones of the samples prepared with different percentages of CNTs up to $0.8 \mathrm{wt} \%$ can clearly be appreciated.

To evaluate the flexural strength of specimens, the modulus of rupture (MOR) was used (Equation 2):

$$
\sigma_{f, \max }=F_{\max } \cdot \frac{3 L}{2 b h^{2}} \quad[\mathrm{MPa}]
$$

in which $L$ is the span, $b$ is the specimen depth, and $h$ is the net ligament height.

After flexural testing, portions of broken prisms were tested in compression, in accordance with ASTM C-348 compressive strength standard (Figure 2). The same MTS servohydraulic machine, with load cell capacity of $100 \mathrm{kN}$, was used.

The accuracy of the testing machine had a tolerance of $\pm 1.0 \%$ with respect to the compressive strength of the specimen.

\section{2 | Physicochemical characterization}

\subsection{1 | X-ray diffraction analysis}

$\mathrm{X}$-ray diffraction was used to determine the main composition of the samples without added CNTs. After compressive tests, the specimens were crushed in an agate mortar with an agate pestle and the powder was sieved with a sieve having openings of a $125 \mu \mathrm{m}$ (120 mesh in the ASTM E11:95 series). The passing fraction, mainly made of binder, was then characterized. X-ray diffraction patterns were recorded in the $5^{\circ}$ to $70^{\circ}$ range in $2 \theta$ with a $0.05^{\circ}$ step size and a time of 2 seconds per step, by means of a Philips PW 3830 instrument equipped with a $\mathrm{Cu} \mathrm{K} \alpha$ anticathode $(\lambda=0.154056 \mathrm{~nm})$.

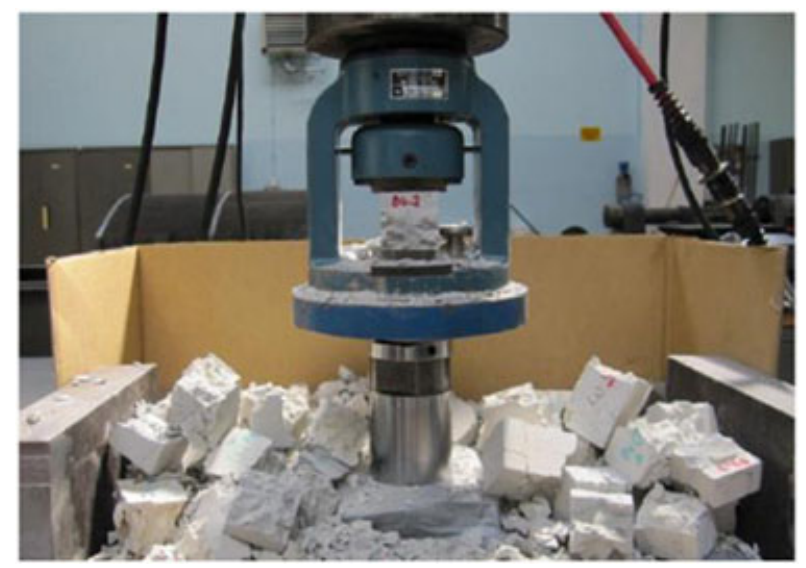

FIGURE 2 Compressive test configuration [Colour figure can be viewed at wileyonlinelibrary.com]

\subsubsection{Field emission scanning electron micros- copy observations}

Field emission scanning electron microscopy (FE-SEM, Zeiss Merlin) was used to observe the microstructure of the samples after hydration. The samples were sputtered with chromium for observations.

\subsubsection{Mercury intrusion porosimetry}

Mercury intrusion porosimetry (MIP) was used on fragments of the broken samples to evaluate the influence of CNTs on the opened porosity. The samples were kept in an oven overnight, prior to each measurement, and Carlo Erba 2000 instrumentation was used.

\subsubsection{Thermogravimetric-differential thermal analysis}

Thermogravimetric-differential thermal analysis (TG-DTA) was performed on hydrated samples by means of a Netzsch STA 409 instrument in static air, from 25 to $1000^{\circ} \mathrm{C}$ with a heating rate of $10^{\circ} \mathrm{C} / \mathrm{min}$.

\section{4 | RESULTS AND DISCUSSION}

\section{1 | Results of mechanical tests}

Three-point bending test results are given in Table 5, and a typical load-CMOD curve is illustrated for some studied compositions (Figures 3-5). With a $0.25 \mathrm{wt} \%$ addition of CNTs to the grout, some agglomerates of CNTs are clearly visible in the matrix, indicating that dispersion was not perfect, even after 3 hours of sonication (Figure 5). Some macropores, due to entrained air bubbles during mixing, are also evident.

Within the context of this work, the results of the tests indicate that CNT addition to the injection mortar Mapei Mape Antique I significantly increases flexural strength as well as fracture energy for CNT additions of $0.25 \mathrm{wt} \%$ (see Figures 6 and 7). Exceeding this amount of CNT addition entails a decrease in $G_{F}$. Similar results were already observed on cement pastes, where additions of up to $0.08 \mathrm{wt} \%$ CNTs greatly increased fracture energy. ${ }^{16}$

Compression tests also confirmed the beneficial effect of CNT addition to the grout, ie an increase of compressive strength was observed up to $0.12 \mathrm{wt} \%$ addition of CNTs with respect to the pristine sample (Figure 8 and Table 5).

\section{2 | Physicochemical characterization results}

The X-ray diffraction (XRD) pattern of the hydrated sample (Figure 9) points to the presence of calcite (main phase) and of portlandite traces $\left(\mathrm{Ca}[\mathrm{OH}]_{2}\right.$, JCPDS card 04-0733). 
TABLE 5 Mortar-multiwalled carbon nanotube (MWCNT) composites investigated, average maximum load in three-point bending test (TPB), fracture energy, $\left(\mathrm{G}_{\mathrm{F}}\right)$ modulus of rupture, (MOR) and maximum load in compression of the studied compositions

\begin{tabular}{|c|c|c|c|c|c|c|c|}
\hline Sample & $\begin{array}{c}\text { Mape } \\
\text { Antique I [g] }\end{array}$ & $\begin{array}{l}\text { Water } \\
{[\mathrm{g}]}\end{array}$ & $\begin{array}{c}\text { CNT Content }^{\mathrm{a}} \\
{[\mathrm{wt} \%]}\end{array}$ & $\begin{array}{c}\text { Max Load } \\
\text { TPB }[N]\end{array}$ & $G_{F}\left[\times 10^{-3} \mathrm{~N} / \mathrm{m}\right]$ & $\begin{array}{l}\text { MOR } \\
{[\mathrm{MPa}]}\end{array}$ & $\begin{array}{c}\text { Max Load Compression } \\
\text { Test }[\mathrm{kN}]\end{array}$ \\
\hline A1 & 1200 & 420 & 0.000 & $60.91 \pm 16.25$ & $20.37 \pm 6.26$ & $0.45 \pm 0.12$ & $22.78 \pm 3.92$ \\
\hline B2 & 1200 & 420 & 0.050 & $100.96 \pm 18.23$ & $23.01 \pm 13.56$ & $0.75 \pm 0.13$ & $27.74 \pm 2.49$ \\
\hline B3 & 1200 & 420 & 0.080 & $102.67 \pm 8.34$ & $28.00 \pm 0.34$ & $0.75 \pm 0.06$ & $30.00 \pm 1.56$ \\
\hline $\mathrm{A} 2$ & 1200 & 420 & 0.250 & $101.76 \pm 43.00$ & $51.08 \pm 1.19$ & $0.74 \pm 0.31$ & $25.19 \pm 6.15$ \\
\hline A3 & 1200 & 420 & 0.500 & $36.88 \pm 22.19$ & $18.86 \pm 1.19$ & $0.31 \pm 0.20$ & $28.62 \pm 1.62$ \\
\hline A4 & 1200 & 420 & 0.800 & $127.4 \pm 14.71$ & $50.20 \pm 0.50$ & $0.93 \pm 0.11$ & $30.01 \pm 1.54$ \\
\hline
\end{tabular}

${ }^{\mathrm{a}} \mathrm{wt} \%$ with respect to binder.
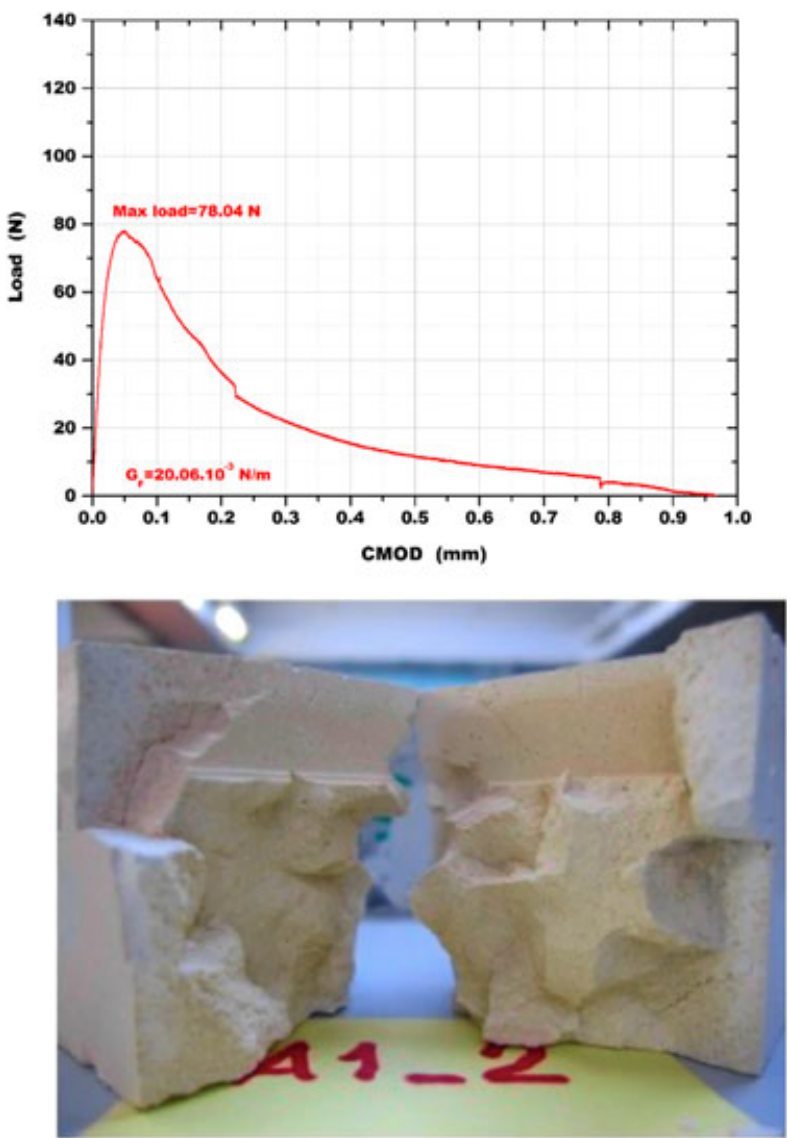

FIGURE 3 Load vs. crack mouth opening displacement (CMOD) curve for pure Mape Antique I sample and broken prisms after flexural test (A1-2) [Colour figure can be viewed at wileyonlinelibrary.com]

Calcium silicate hydrate, a reaction product of portlandite and pozzolan, is difficult to detect by X-ray analysis, due to its low degree of crystallinity. It is characterized by a wide band of peaks in the range of $2 \theta 28$ to $33^{\circ} .^{26}$ These results are in line with producer specifications, ie it is a cement-free fillerized hydraulic binder. ${ }^{24}$
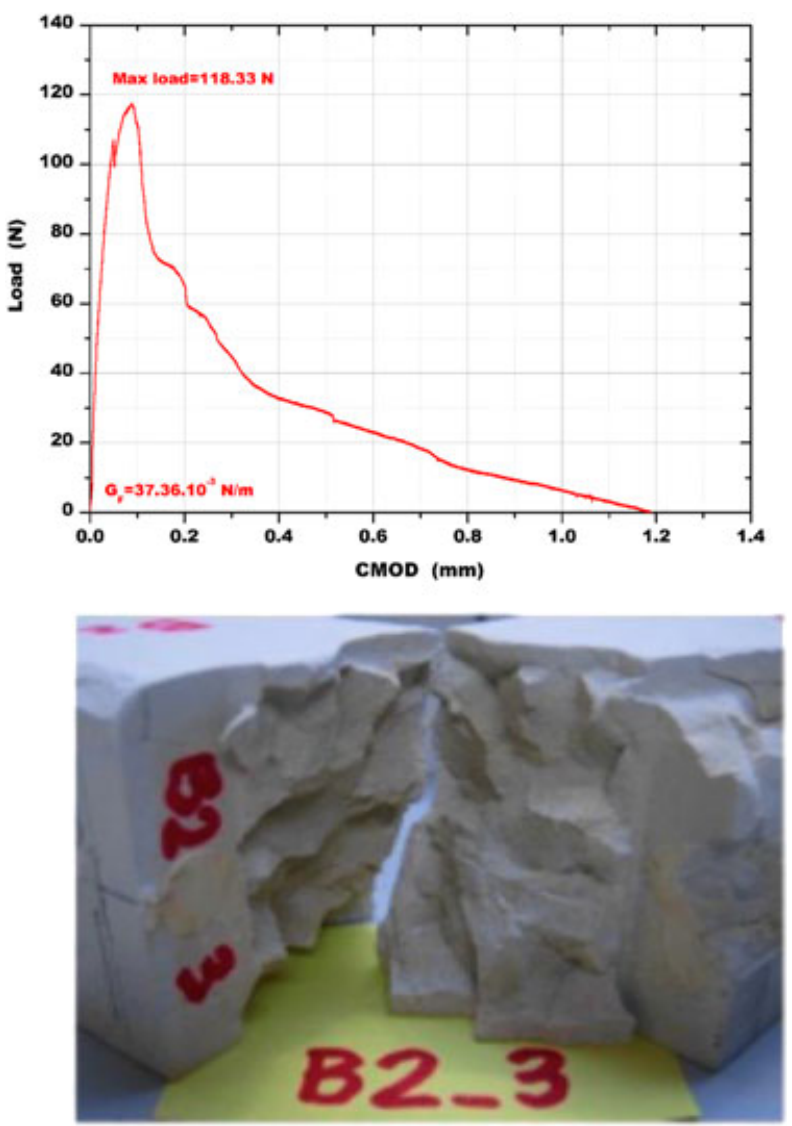

FIGURE 4 Load vs. crack mouth opening displacement (CMOD) curve for Mape Antique I + $0.05 \mathrm{wt} \%$ of carbon nanotubes (CNTs) and broken prisms after flexural test (B2-3) [Colour figure can be viewed at wileyonlinelibrary.com]

Mercury intrusion porosimetry showed an average mortar density, after curing time, of $1.69 \pm 0.05 \mathrm{~g} / \mathrm{cm}^{3}$. Mercury intrusion porosimetry showed that increasing CNT content in the grout slightly lowers average pore size and porosity for additions up to $0.12 \mathrm{wt} \%$ (Table 6). This result can 

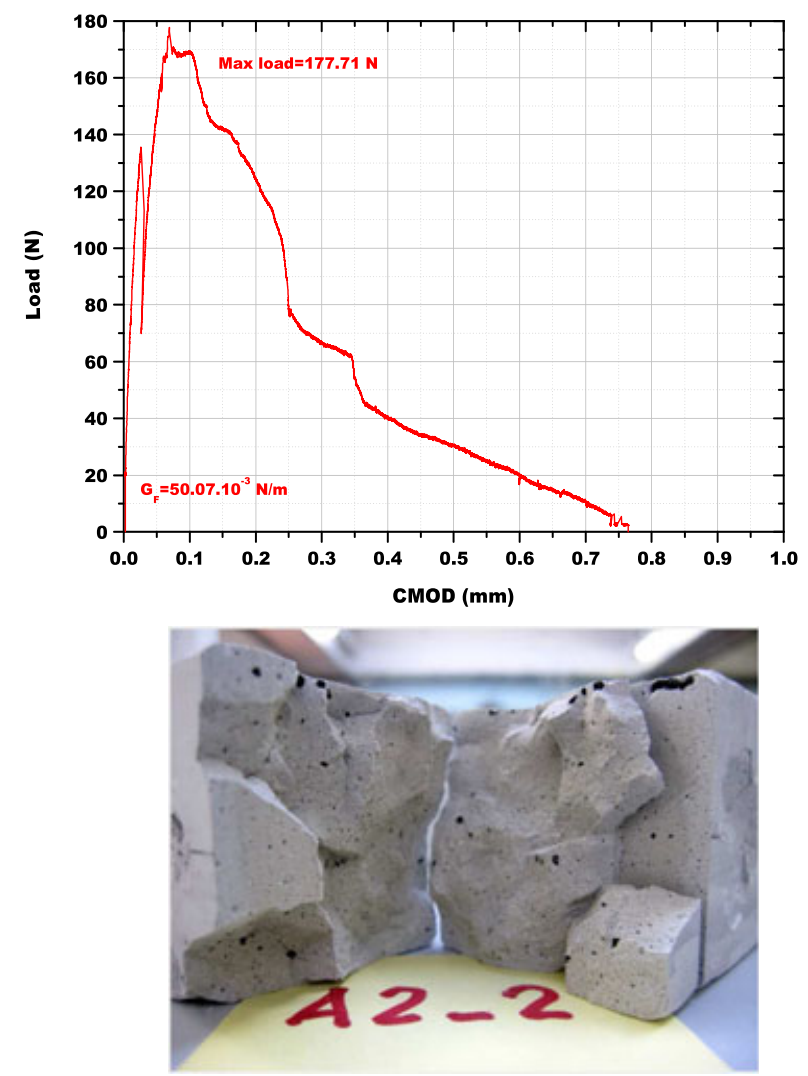

FIGURE 5 Load vs. crack mouth opening displacement (CMOD) curve for Mape Antique I + $0.25 \mathrm{wt} \%$ of carbon nanotubes (CNTs) and broken prisms after flexural test (A2-2) [Colour figure can be viewed at wileyonlinelibrary.com]

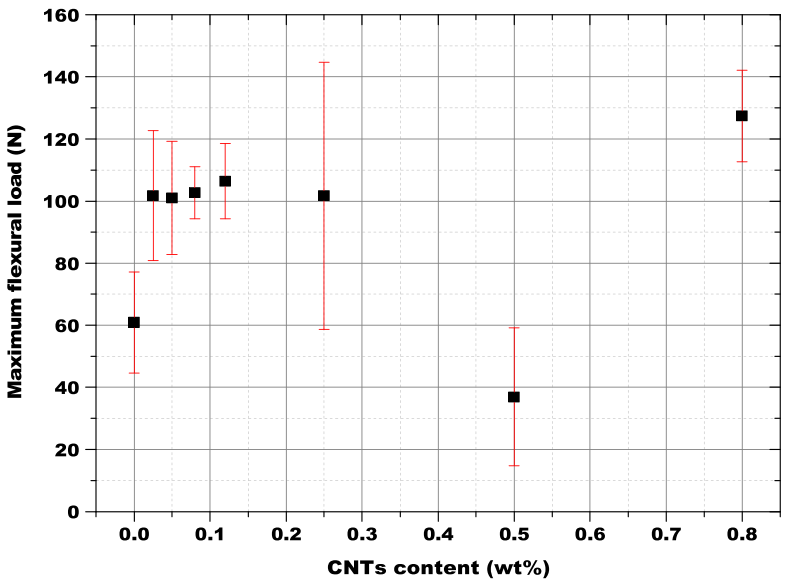

FIGURE 6 Influence of carbon nanotube (CNT) content on flexural strength for the target grout [Colour figure can be viewed at wileyonlinelibrary.com]

probably be correlated to FE-SEM observations where, with an addition of up to $0.12 \mathrm{wt} \%$ CNTs, no CNT agglomerate was clearly visible in the samples. These results are also in agreement with literature data where cement pastes containing CNTs present lower porosity and more uniform

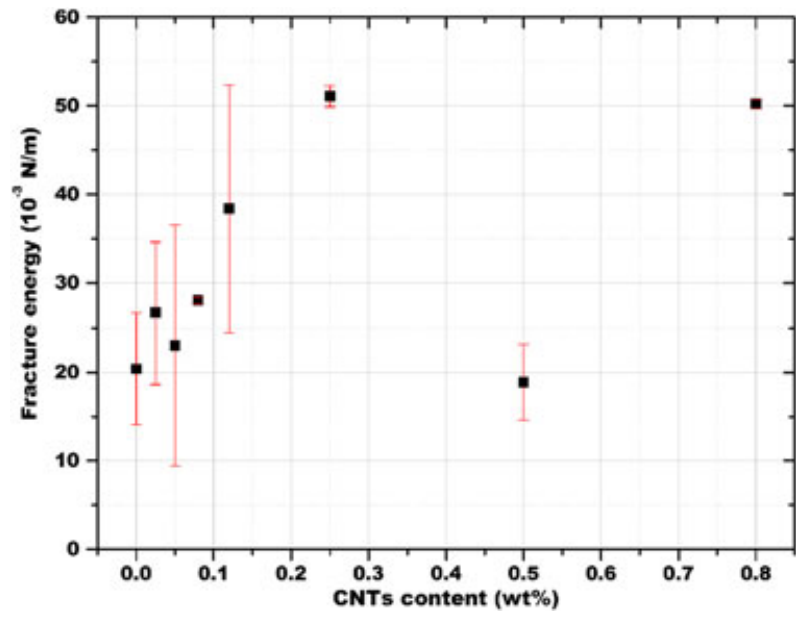

FIGURE 7 Influence of carbon nanotube (CNT) content on average fracture energy for the target grout [Colour figure can be viewed at wileyonlinelibrary.com]

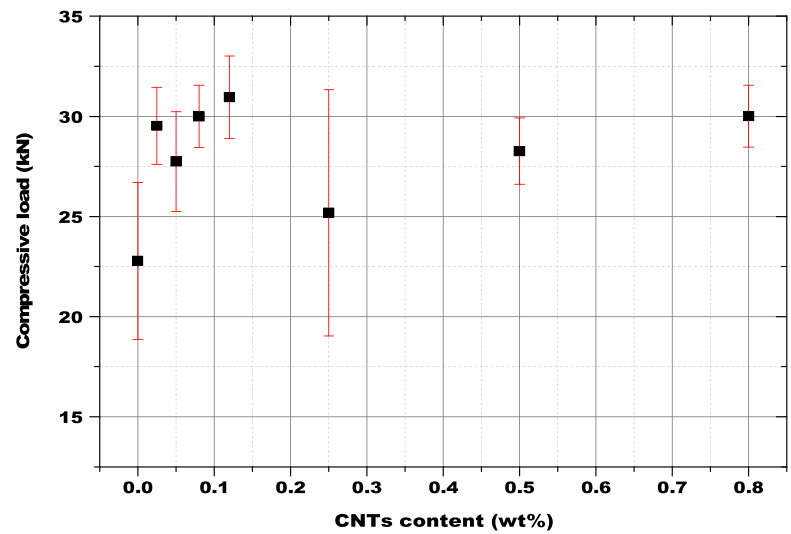

FIGURE 8 Influence of carbon nanotube (CNT) content on compressive strength for the target grout [Colour figure can be viewed at wileyonlinelibrary.com]

pore size distribution. ${ }^{27}$ These results are in line with mechanical testing where an increase of flexural and of compressive strength was observed for additions up to $0.12 \mathrm{wt} \%$ of CNTs (Table 5).

Thermogravimetric-differential thermal analysis curve (Figure 10) indicates that hydrated Mapei Mape Antique I mortar is just composed of mineral components, as no exothermic peak due to thermal degradation of any organic fraction was observed. Three main mass losses were observed between room temperature and $950^{\circ} \mathrm{C}$ (Figure 10).associated with 2 endothermic peaks (the first is a very weak broad peak at $738^{\circ} \mathrm{C}$ with a weight loss of $1.9 \%$ due to recarbonated calcite, while the second is intense at $902^{\circ} \mathrm{C}$ with a weight loss of $19.1 \%$ due to calcite decomposition). Usually, weight losses corresponding to temperatures around $120^{\circ} \mathrm{C}$ are attributed to the loss of physically adsorbed water in samples. 


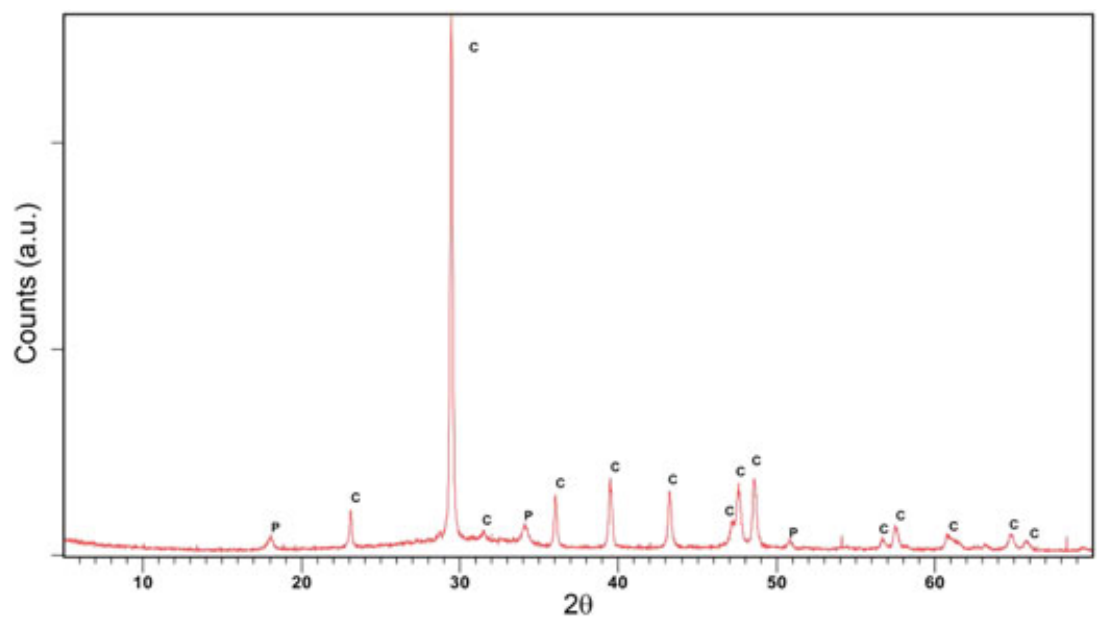

FIGURE 9 X-ray diffraction (XRD) pattern of the hydrated pristine sample $(\mathrm{C}$ indicates calcite; $\mathrm{P}$, portlandite) [Colour figure can be viewed at wileyonlinelibrary.com]
TABLE 6 Mercury intrusion porosimetry results (average of 2 measurements)

\begin{tabular}{lccc} 
Sample & $\begin{array}{c}\text { CNT Content } \\
{[\mathbf{w t} \%]}\end{array}$ & $\begin{array}{c}\text { Average } \\
\text { Porosity [\%] }\end{array}$ & $\begin{array}{c}\text { Average Pore Size } \\
\text { (radius) }[\boldsymbol{\mu m}]\end{array}$ \\
\hline A1 & 0.00 & 37.1 & 0.038 \\
B4 & 0.12 & 35.2 & 0.027 \\
A2 & 0.25 & 36.3 & 0.030 \\
A4 & 0.80 & 38.6 & 0.027 \\
\hline
\end{tabular}

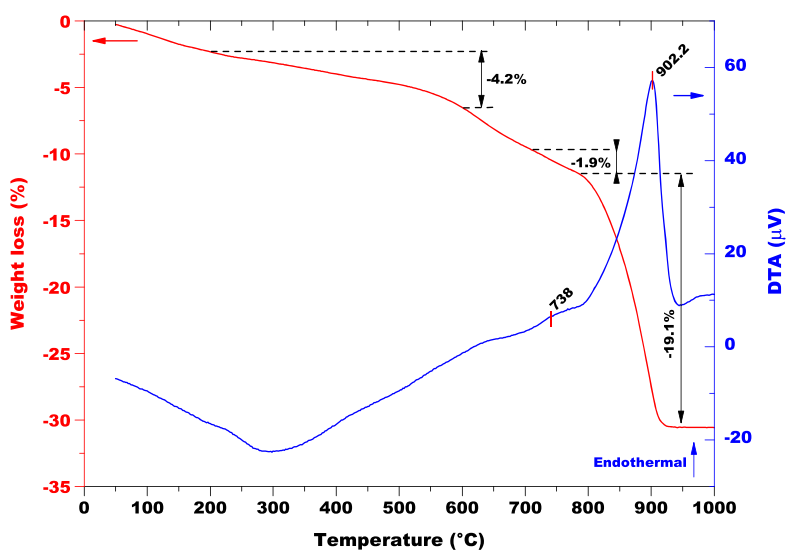

FIGURE 10 Themogravimetric-differential thermal analysis (TG-DTA) curve of Mape Antique I hydrated grout [Colour figure can be viewed at wileyonlinelibrary.com]

Weight losses in the temperature range of 120 to $200^{\circ} \mathrm{C}$ and 200 to $600^{\circ} \mathrm{C}$ correspond to the loss of bound and of chemically bound water, respectively, when there are no hydrated salts in the sample. ${ }^{28,29}$

As a consequence, these dehydration reactions are characteristic of the presence of hydraulic compounds in a sample. Weight losses at reaction temperatures near $750^{\circ} \mathrm{C}$ render the loss of $\mathrm{CO}_{2}$ from recarbonated lime, not from primary calcite. ${ }^{28}$ This is because recarbonated calcite decomposes at a lower temperature than it does naturally. In fact, natural calcite possesses large crystals, while when recarbonated, it is made of microcrystals. Calcite is also due to the filler used (50 wt $\%$, as declared by the producer). There was a mass loss of $4.2 \%$ between $200^{\circ}$ and $600^{\circ} \mathrm{C}$, which is in line with observations in artificial pozzolanic mortars. ${ }^{30,31}$ Finally, contrary to XRD findings, portlandite was not detected by TG-DTA, probably because of a complete reaction with pozzolan when the sample was analysed by XRD or because it was already carbonated when TG-DTA was performed. ${ }^{32}$ These results confirm the specifications provided by the grout producer. ${ }^{24}$

Carbon nanotube crack bridging and pullout was clearly shown by FE-SEM observations in the binder matrix (Figures 11, 12, and 13). This behavior is well known in cement pastes, where CNTs act as bridges across cracks and voids and form a network that transfers the load in tension. ${ }^{7,8}$

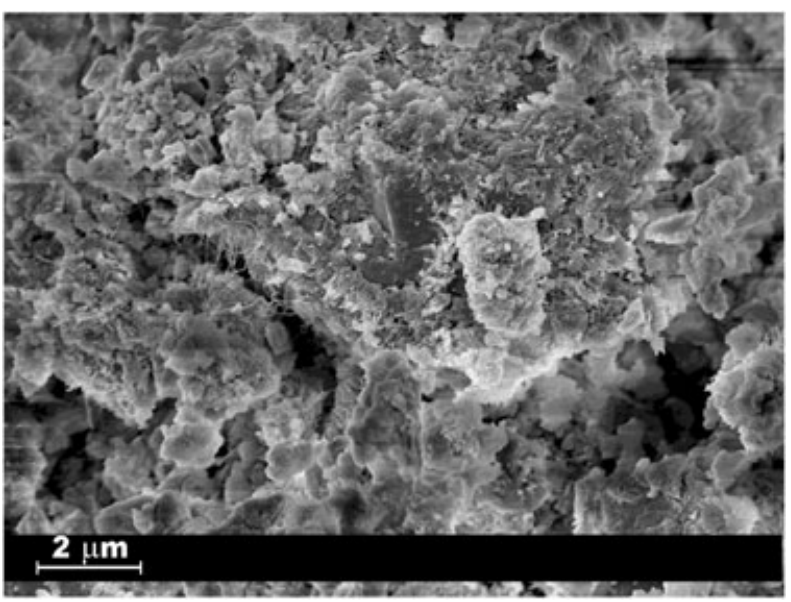

FIGURE 11 Field emission scanning electron microscopy (FE-SEM) micrograph of carbon nanotube (CNT) pullout from the mortar matrix: sample containing $0.8 \mathrm{wt} \% \mathrm{CNTs}$ 


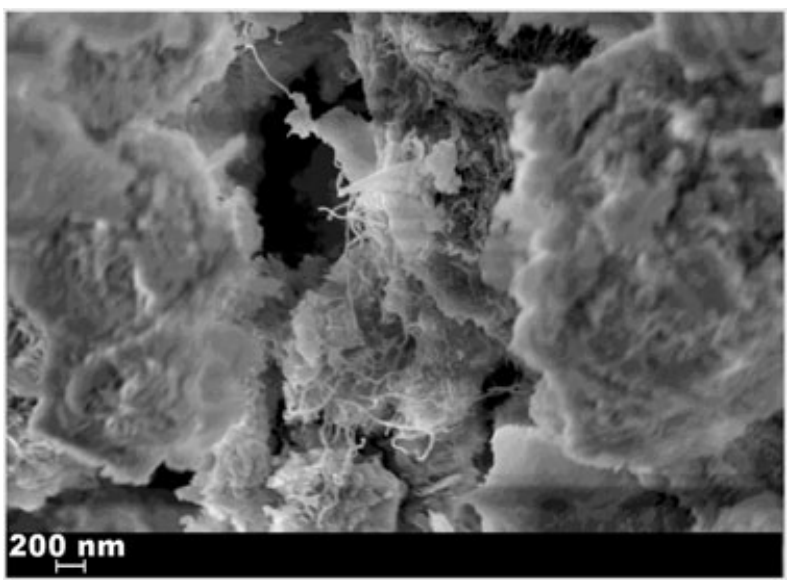

FIGURE 12 Field emission scanning electron microscopy (FESEM) micrograph of carbon nanotube (CNT) pullout from the mortar matrix: sample containing $0.25 \mathrm{wt} \% \mathrm{CNTs}$

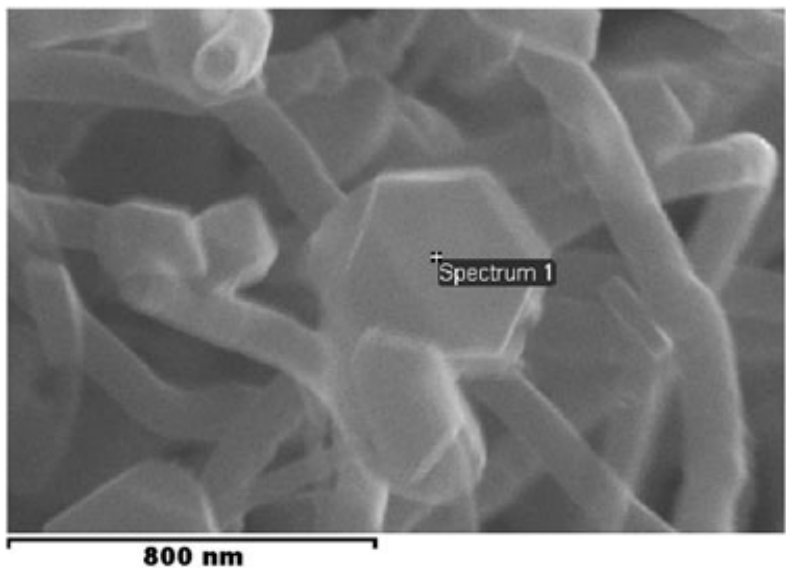

FIGURE 13 Field emission scanning electron microscopy (FESEM) micrograph of carbon nanotubes (CNTs) with silicon-rich crystals

It is evident from these observations that CNTs can interact with fracture development by arresting the growth of microcracks and can delay the propagation of microcracks, thus impeding their coalescence to form the first macrocrack. Therefore, the addition of CNTs also provides an increase in fracture energy, as observed (Table 5).

Figure 13 shows crystals bound to the CNTs. Energydispersive X-ray analysis (spectrum 1 in Figure 13) indicates the presence of carbon and of silicon only. The presence of nanotubes means that the carbon can be ascribed to them, while silicon is probably due to a fine grain of quartz (from sand in the grout). The important conclusion that can be drawn from these observations is that other crystals on the left of the same image are visible and are also bound to the CNTs. Therefore, as observed in cementitious materials, CNTs are probably able to chemically bind hydrated phases in a hydraulic binder. ${ }^{13-15}$
To sum up, grout with added CNTs led to a reduction in nanoporosity (Table 6), activated the crack bridging and pullout mechanism (Figures 11 and 12), and acted as nucleation sites for hydration products (Figure 13). That is to say, 3 of the 4 reinforcing mechanisms observed in cementitious matrices $^{7-17}$ were found in a hydraulic injection grout.

\section{5 | CONCLUSIONS}

This is the first time that CNTs have been added to a hydraulic injection grout. The test results show that these additions increased flexural and compressive strengths, as well as fracture energy, with a CNT content of up to $0.12 \mathrm{wt} \%$ of the binder.

A visual analysis of the specimen's fractured surfaces clearly showed that cracks seldom started from the notch. A very complex fractured surface was generated, thus delaying specimen the failure. The presence of CNTs increased fracture energy without significantly modifying the complexity of fracture geometry. The results are in agreement with literature, which mentions the beneficial effects that fibres and CNTs have on the resulting cementitious composites. The addition of CNTs to grout led to a reduction of nanoporosity, induced a crack bridging mechanism, and acted as nucleation sites for hydration products, ie, 3 of the 4 reinforcing mechanisms observed in cementitious matrices.

The nonlinearity of the increments in fracture energy and the scatter in the results are, in general terms, due to random factors related to specimen preparation and, particularly, by uneven CNT dispersion in fresh mortar paste, as shown by the fracture images of the specimens tested.

This investigation is a first step in a process to test the effect of CNT addition to grout at different scales, with a view to making, eventually, a more substantiated assessment of their practical use. This work must now be completed with rheological studies to evaluate the effect of CNTs on viscosity.

\section{REFERENCES}

1. Van Gemert D, Van Rickstal F, Ignoul S, Toumbakari E-E, Van Balen K. (2005) Structural consolidation and strengthening of masonry: historical overview and evolution. Available online: http://staff.ttu.ee/ voltri/Erikursus/Kivikonst\%20tugevdamine.pdf. consulted on March, 20th 2017.

2. Sorrentino L, Liberatore L, Decanini LD, Liberatore D. The performance of churches in the 2012 Emilia earthquakes. Bull Earthquake Eng. 2014;12:2299-2331.

3. Binda L, Modena C, Baronio G, Abbaneo S. Repair and investigation techniques for stone masonry walls. Construct Build Mater. 1997;11:133-142. 
4. Bras A, Henriques FMA, Cidade MT. Effect of environmental temperature and fly ash addition in hydraulic lime grout behavior. Construct Build Mater. 2010;24:1511-1517.

5. Toumbakari E-E (2002). Lime-Pozzolan-cement grouts and their structural effects on composite masonry walls. Ph.D. thesis. K.U. Leuven, Leuven, Belgium.

6. Liew KM, Kai MF, Zhang LW. Carbon nanotube reinforced cementitious composites: an overview. Composites Part A. 2016;91:301-323.

7. Chen SJ, Zou B, Collins F, Zhao XL, Majumber M, Duan WH. Predicting the influence of ultrasonication energy on the reinforcing efficiency of carbon nanotubes. Carbon. 2014;77:1-10.

8. Parveen S, Rana S, Fangueiro R, Paiva MC. Microstructure and mechanical properties of carbon nanotube reinforced cementitious composites developed using a novel dispersion technique. Cem Concr Res. 2015;73:215-227.

9. Chowdhury SC, Haque BZ, Okabe T, Gillespie JW. Modeling the effect of statistical variations in length and diameter of randomly oriented CNTs on the properties of CNT reinforced nanocomposites. Composites Part B Eng. 2012;43(4):1756-1762.

10. Konsta-Gdoutos MS, Metaxa ZS, Shah SP. Multi-scale mechanical and fracture characteristics and early-age strain capacity of high performance carbon nanotube/cement nanocomposites. Cem Concr Compos. 2010;32(2):110-115.

11. Li GY, Wang PM, Zhao X. Mechanical behavior and microstructure of cement composites incorporating surface-treated multi-walled carbon nanotubes. Carbon. 2005;43:1239-1245.

12. Kendall K, Howard A, Birchall J, Pratt P, Proctor B, Jefferis S. The relation between porosity, microstructure and strength, and the approach to advanced cement-based materials [and discussion]. Philos Trans R Soc Lond A: Math, Phys Eng Sci. 1983;310 (1511):139-513.

13. Xu S, Liu J, Li Q. Mechanical properties and microstructure of multi-walled carbon nanotube-reinforced cement paste. Construct Build Mater. 2015;76:16-23.

14. Zhou X, Shin E, Wang K, Bakis C. Interfacial damping characteristics of carbon nanotube-based composites. Compos Sci Technol. 2004;64(15):2425-2437.

15. Chandra R, Singh S, Gupta K. Damping studies in fiber-reinforced composites-a review. Compos Struct. 1999;46(1):41-51.

16. Singh AP, Gupta BK, Mishra M, Chandra A, Mathur R, Dhawan S. Carbon nanotube/cement composites with exceptional electromagnetic interference shielding properties. Carbon. 2013;56:86-96.

17. Makar JM, Chan GW. Growth of cement hydration products on single-walled carbon nanotubes. J Am Ceram Soc. 2009;92 (6): 1303-1310

18. Cao M, Zhang C, Wei J. Microscopic reinforcement for cement based composite materials. Construct Build Mater. 2013;40:14-25.
19. Gallo P, Sumigawa T, Kitamura T, Berto F. Evaluation of the strain energy density control volume for a nanoscale singular stress field, fatigue and fracture of engineering materials and structures. Fatigue Fract Engng Mater Struct. 2016;2016 (39):1557-1564.

20. Berto F. A brief review of some local approaches for the failure assessment of brittle and quasi-brittle materials. Adv Mater Sci Engng, Article ID 930679. 2014;10

21. Guinea GV, Planas J, Elices M. Measurement of the fracture energy using three-point bend tests: part 1-influence of experimental procedures. Mater Struc. 1992;25:212-218.

22. Musso S, Tulliani JM, Ferro G, Tagliaferro A. Influence of carbon nanotubes structure on the mechanical behaviour of cement composites. Compos Sci Technol. 2009;69:1985-1990.

23. Figarol A, Pourchez J, Boudard D, et al. Biological response to purification and acid functionalization of carbon nanotubes. J Nanopart Res. 2014;16(7):2507

24. http://www.mapei.com/public/COM/products/601_mape-antique_i_ gb.PDF. Consulted on July, 20th 2016.

25. RILEM 50-FMC (1986). Committee fracture mechanics of concrete determination of the fracture energy of mortar and concrete by means of three point tests on notched beams.

26. Taylor HFW. Cement Chemistry. London: Academic Press; 1990.

27. Wang B, Han Y, Liu S. Effect of highly dispersed carbon nanotubes on the flexural toughness of cement-based composites. Construct Build Mater. 2013;46:8-12.

28. Moropoulou A, Bakolas A, Bisbikou K. Physico-chemical adhesion and cohesion bonds in joint mortars imparting durability to the historic structures. Construct Build Mater. 2000;14(1):35-46.

29. Katsioti M, Gkanis D, Pipilikaki P, et al. Study of the substitution of limestone filler with pozzolanic additives in mortars. Construct Build Mater. 2009;23:1960-1965.

30. Moropoulou A, Bakolas A, Aggelakopoulou E. Evaluation of pozzolanic activity of natural and artificial pozzolans by thermal analysis. Thermochim Acta. 2004;420:135-140.

31. Moropoulou A, Bakolas A, Anagnostopoulou S. Composite materials in ancient structures. Cement Concrete Compos. 2005;27:295-300.

32. Moropoulou A, Bakolas A, Moundoulas P, Aggelakopoulou E, Anagnostopoulou S. Strength development and lime reaction in mortars for repairing historic masonries. Cement \& Concrete Compos. 2005;27:289-294.

How to cite this article: Restuccia L, Lopez A, Ferro GA, Liberatore D, Tulliani JM. An investigation of the beneficial effects of adding carbon nanotubes to standard injection grout. Fatigue Fract Eng Mater Struct. 2018;41:119-128. https://doi.org/10.1111/ffe.12663 